\title{
Compositional Sequence Determination of Acrylamide/Alkyl Acrylate Copolymers by NMR Spectroscopy
}

\author{
Ajaib Singh Brar, ${ }^{\dagger}$ Munia MukherJeE, $^{*}$ and Saroj Kumar ChatterJeE* \\ Department of Chemistry, Indian Institute of Technology, \\ Hauz Khas, New Delhi 110 016, India \\ * Department of Chemistry, Delhi University, Delhi 110007, India
}

(Received February 23, 1998)

\begin{abstract}
Acrylamide/ethyl acrylate (A/E) and acrylamide/butyl acrylate (A/B) copolymers were prepared by free radical solution polymerization. Copolymer composition was determined from the nitrogen content of the copolymers. The copolymer composition data were used to determine the reactivity ratios for the copolymerization of $\mathrm{A} / \mathrm{E}$ and $\mathrm{A} / \mathrm{B}$ copolymer systems by Kelen-Tüdos (KT) and nonlinear error in variables (EVM) methods. The reactivity ratios obtained are $r_{\mathrm{A}}=0.59 \pm 0.05$ and $r_{\mathrm{E}}=0.91 \pm 0.09$ for $\mathrm{A} / \mathrm{E}$ copolymer system and $r_{\mathrm{A}}=0.71 \pm 0.05$ and $r_{\mathrm{B}}=1.27 \pm 0.08$ for $\mathrm{A} / \mathrm{B}$ copolymer system. Microstructures in terms of the triad distribution from ${ }^{13} \mathrm{C}$ NMR spectroscopy were found to be in good agreement with those calculated from the theoretical models and Monte Carlo (MC) simulations. MC simulations were also used to determine the degree of polymerization of the two copolymer systems.

KEY WORDS Microstructure / Acrylamide/Alkyl Acrylate Copolymers / Nuclear Magnetic Resonance Spectroscopy / Monte Carlo Simulations /
\end{abstract}

Detailed understanding of the microstructure of synthetic vinyl polymers is of fundamental and practical significance. The macroscopic physicomechanical and physicochemical properties of these materials are inherently dependent on chain microstructures. ${ }^{1,2}$ Various mechanical properties of the polymers like viscous flow, refractive index, thermal expansivity, crystallization, etc. depend on the $T_{\mathrm{g}}$ of the polymers which in turn is affected by pendant groups and sequence distribution of comonomer units. ${ }^{3,4}$ Acrylamide polymers are an important class of materials because of their use in many industrial applications such as base and top coats in leather industry, ${ }^{5}$ flocculants in industrial wastes, papermaking and mining, etc. Many workers have reported the reactivity ratios and microstructures of acrylamide copolymers by ${ }^{1} \mathrm{H}$ and ${ }^{13} \mathrm{C}$ NMR spectroscopy. ${ }^{6-9}$ The acrylamide/ethyl acrylate (A/E) and acrylamide/butyl acrylate (A/B) copolymers were synthesised by solution polymerization. The reactivity ratios and comonomer sequence distribution of $\mathrm{A} / \mathrm{E}$ and $\mathrm{A} / \mathrm{B}$ copolymers using ${ }^{13} \mathrm{C}$ NMR spectroscopy is reported in this article.

\section{EXPERIMENTAL}

Ethyl acrylate (Central Drug House, India) and butyl acrylate (Central Drug House, India) were distilled under reduced pressure and stored below $5^{\circ} \mathrm{C}$. Acrylamide (Sisco Research Laboratories, India) was recrystallized twice from chloroform. $N, N$-Dimethyl formamide (DMF) (Merck, Germany) was distilled and dried.

A series of $\mathrm{A} / \mathrm{E}$ and $\mathrm{A} / \mathrm{B}$ copolymers containing different mole percent of the respective comonomers in feed were prepared by solution polymerization in DMF at $65^{\circ} \mathrm{C}$ using benzoyl peroxide $(0.5 \mathrm{w} / \mathrm{v} \%)$ as the initiator. The conversion was kept below $10 \%$ by precipitating the copolymer in water. The copolymers

\footnotetext{
${ }^{\dagger}$ To whom all correspondence should be addressed.
}

were further dissolved in DMF and reprecipitated in water and vacuum dried.

The copolymer composition was determined by estimating the nitrogen content of the copolymers. The $\mathrm{C}, \mathrm{H}$, and $\mathrm{N}$ analyses were done on a Perkin-Elmer 240C Elemental Analyzer.

The ${ }^{13} \mathrm{C}$ NMR spectra were recorded on a Bruker $300 \mathrm{MHz}$ spectrometer in dimethyl sulfoxide (DMSO)- $d_{6}$ at room temperature using tetramethylsilane (TMS) as the internal standard reference. A $2 \mathrm{~s}$ relaxation delay was used for ${ }^{13} \mathrm{C}$ NMR spectra recording. The concentration of the sample for NMR recording was approximately $65 \mathrm{mg} \mathrm{ml}^{-1}$. The details of measuring the fractional peak area using a Lorentzian shaped curve fitting computer program are described elsewhere. ${ }^{10}$ All regressions converged to $\chi^{2}<1$.

\section{RESULTS AND DISCUSSION}

\section{Reactivity Ratio Determination}

The compositions of $\mathrm{A} / \mathrm{E}$ and $\mathrm{A} / \mathrm{B}$ copolymers were estimated by the percentage nitrogen content in the copolymers. Tables I and II show the comonomer mole fractions in the feed, copolymers, percentage nitrogen of the copolymers and percentage conversion for the $\mathrm{A} / \mathrm{E}$ and A/B copolymers, respectively. Copolymer composition data were used to calculate the terminal model reactivity ratios by the Kelen-Tüdos $(\mathrm{KT})^{11}$ method and error in variable (EVM) method $^{12}$ using the RREVM computer program. The reactivity ratios obtained by the KT method were used as the initial estimates of values in the RREVM program. Error in measuring the comonomer composition in feed and copolymer was taken as $1 \%$ and $3 \%$, respectively. The reactivity ratios obtained by the KT method and RREVM program for the $\mathrm{A} / \mathrm{E}$ and $\mathrm{A} / \mathrm{B}$ copolymer systems are summarized in Table III. Variation of the copolymer composition obtained from the copolymer equation using the terminal model reactivity ratios for the two copolymer sys- 
tems namely $\mathrm{A} / \mathrm{E}$ and $\mathrm{A} / \mathrm{B}$ along with the experimental points $^{13}$ is shown in Figures $1 \mathrm{a}$ and $1 \mathrm{~b}$.

\section{${ }^{13}$ C NMR Studies}

Acrylamide/Ethyl Acrylate $(A / E)$ Copolymers. The ${ }^{13} \mathrm{C}$ NMR spectrum of $\mathrm{A} / \mathrm{E}$ copolymer $(\mathrm{A}=50 \mathrm{~mol} \%$ in

Table I. Feed mole fractions, percent nitrogen, copolymer compositions, and percentage conversions for acrylamide/ethyl acrylate $(\mathrm{A} / \mathrm{E})$ copolymer

\begin{tabular}{cccccc}
\hline $\begin{array}{c}\text { Sample } \\
\text { No. }\end{array}$ & $f_{\mathrm{A}}$ & $\begin{array}{c}\text { Percent } \\
\text { nitrogen }\end{array}$ & $F_{\mathrm{A}}{ }^{\mathrm{a}}$ & $F_{\mathrm{A}}{ }^{\mathbf{b}}$ & $\begin{array}{c}\text { Percentage } \\
\text { conversion }\end{array}$ \\
\hline 1 & 0.30 & 4.42 & 0.29 & 0.29 & 4.1 \\
2 & 0.40 & 5.70 & 0.36 & 0.38 & 5.8 \\
3 & 0.50 & 7.38 & 0.46 & 0.47 & 2.2 \\
4 & 0.55 & 8.24 & 0.50 & 0.50 & 3.6 \\
5 & 0.60 & 8.76 & 0.53 & 0.54 & 7.6 \\
6 & 0.65 & 9.96 & 0.59 & 0.60 & 4.3 \\
7 & 0.70 & 10.78 & 0.63 & 0.61 & 5.1 \\
8 & 0.75 & 12.77 & 0.72 & 0.69 & 3.9 \\
\hline
\end{tabular}

${ }^{a}$ Copolymer composition calculated from nitrogen analysis. ${ }^{b} \mathrm{Co}-$ polymer composition calculated from triad fractions.

Table II. Feed mole fractions, percent nitrogen, copolymer compositions, and percentage conversions for acrylamide/butyl acrylate $(\mathrm{A} / \mathrm{B})$ copolymer

\begin{tabular}{cccccc}
\hline $\begin{array}{c}\text { Sample } \\
\text { No. }\end{array}$ & $f_{\mathrm{A}}$ & $\begin{array}{c}\text { Percent } \\
\text { nitrogen }\end{array}$ & $F_{\mathrm{A}}{ }^{\mathrm{a}}$ & $F_{\mathrm{A}}{ }^{\mathrm{b}}$ & $\begin{array}{c}\text { Percentage } \\
\text { conversion }\end{array}$ \\
\hline 1 & 0.30 & 3.05 & 0.25 & 0.26 & 7.3 \\
2 & 0.40 & 4.22 & 0.33 & 0.34 & 4.5 \\
3 & 0.50 & 6.11 & 0.45 & 0.44 & 4.2 \\
4 & 0.55 & 6.62 & 0.48 & 0.47 & 5.9 \\
5 & 0.60 & 7.48 & 0.52 & 0.54 & 6.6 \\
6 & 0.65 & 8.38 & 0.57 & 0.60 & 2.8 \\
7 & 0.70 & 9.60 & 0.63 & 0.65 & 6.2 \\
8 & 0.75 & 9.97 & 0.65 & 0.69 & 5.8 \\
\hline
\end{tabular}

${ }^{a}$ Copolymer composition calculated from nitrogen analysis. ${ }^{b} \mathrm{Co}-$ polymer composition calculated from triad fractions.

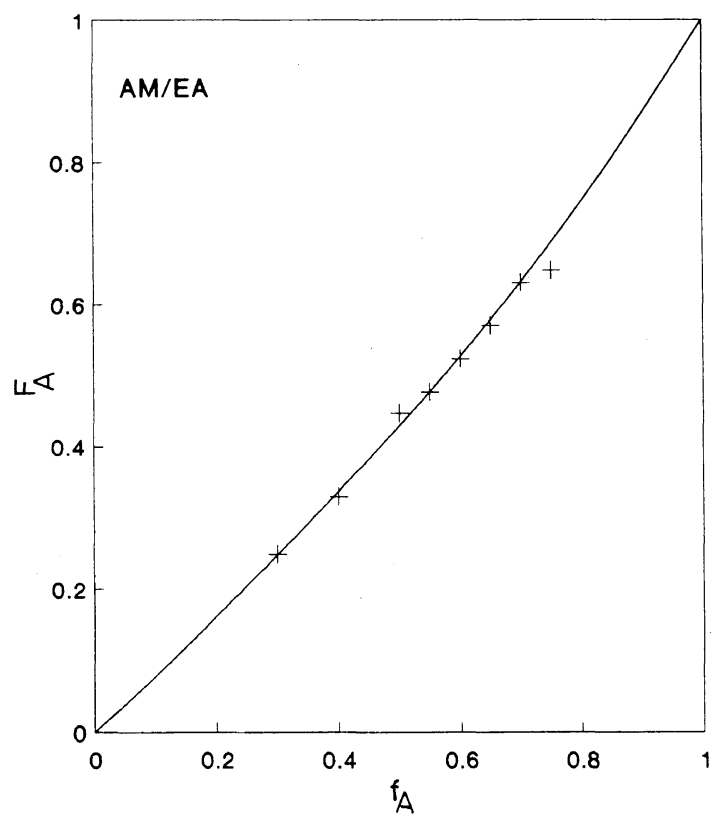

(a) copolymer) along with the signal assignments is shown in Figure 2. Resonance signals of the carbonyl carbons $(\backslash \mathrm{C}=\mathrm{O})$ of $\mathrm{A}$ - and E-monomeric units appear as multiplet around $\delta 175.6-\delta 178.0 \mathrm{ppm}$ and $\delta 174.0-$ $\delta 176.2 \mathrm{ppm}$, respectively, showing sensitivity to compositional sequences. The methylene $\left(-\mathrm{CH}_{2}\right)$ carbon of A- and E-units resonance around $\delta 34.0-\delta 38.0 \mathrm{ppm}$. The methine $(-\mathrm{CH})$ carbon of $\mathrm{A}-$ and E-units resonance around $\delta 39.0-\delta 45.0 \mathrm{ppm}$ which overlaps with the resonance signal of DMSO- $d_{6} .-\mathrm{OCH}_{2}$ and $-\mathrm{CH}_{3}$ signals of the E-unit appear as singlets at $\delta 60.59 \mathrm{ppm}$ and $\delta 14.59 \mathrm{ppm}$ respectively showing insensitivity towards compositional sequences. The carbonyl carbon of A- and E-units can be separated into three distinct regions. The signals around $\delta 174.0-\delta 174.7 \mathrm{ppm}$ decrease and those around $\delta 175.2-\delta 176.2 \mathrm{ppm}$ increase with increase in the concentration of the A-units in the copolymer. However, the signal around $\delta 174.7-\delta 175.1 \mathrm{ppm}$ initially increases, goes through a maximum and then decreases with increase in feed mole fraction of acrylamide $\left(f_{\mathrm{A}}\right)$ as shown in Figure 3. These three regions can thus be assigned as EEE, EEA(AEE), and AEA from high to low field.

On the basis of change in the intensity of resonance signals, with copolymer composition the A-centered triads were assigned. The resonance signals around $\delta 175.6-\delta 176.3, \delta 176.3-\delta 177.0$, and $\delta 177.0-\delta 178.1$ ppm were assigned as EAE, EAA(AAE), and AAA, respectively (Figure 3).

Table III. Reactivity ratios for $\mathrm{A} / \mathrm{E}$ and $\mathrm{A} / \mathrm{B}$ copolymers

\begin{tabular}{cccc}
\hline $\begin{array}{c}\text { Reactivity } \\
\text { ratio }\end{array}$ & KT Method & RREVM & Copolymer system \\
\hline$r_{\mathrm{A}}$ & $0.59 \pm 0.06$ & $0.59 \pm 0.05$ & Acrylamide/Ethyl \\
$r_{\mathrm{E}}$ & $0.91 \pm 0.08$ & $0.91 \pm 0.09$ & acrylate \\
$r_{\mathrm{A}}$ & $0.69 \pm 0.07$ & $0.71 \pm 0.05$ & Acrylamide/Butyl \\
$r_{\mathrm{B}}$ & $1.24 \pm 0.10$ & $1.27 \pm 0.08$ & acrylate
\end{tabular}

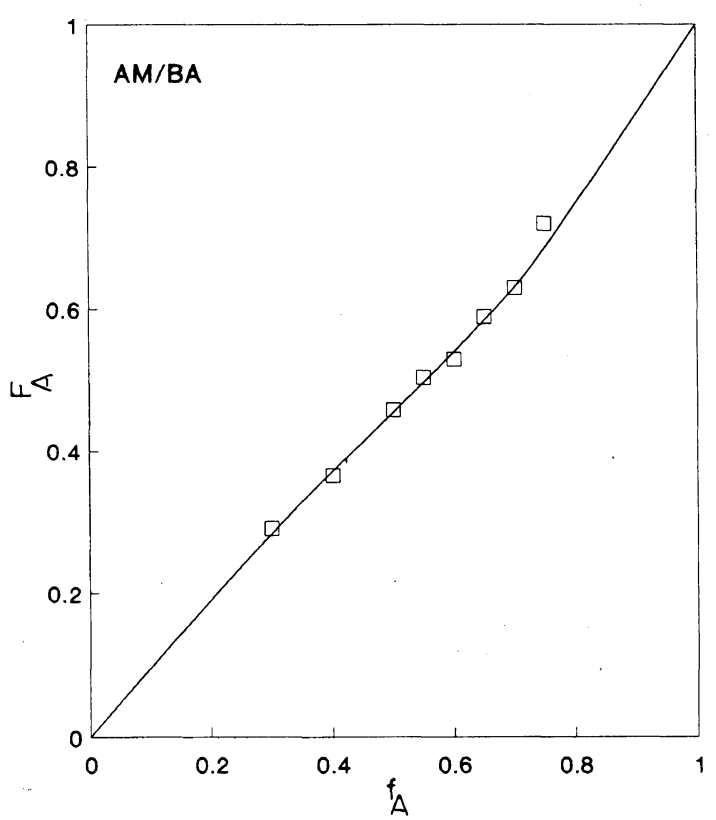

(b)

Figure 1. Theoretical composition curves for (a) A/E and (b) A/B copolymer systems along with experimentally determined copolymer composition (symbols). 
A. S. Brar, M. MukherJee, and S. K. ChatterJee

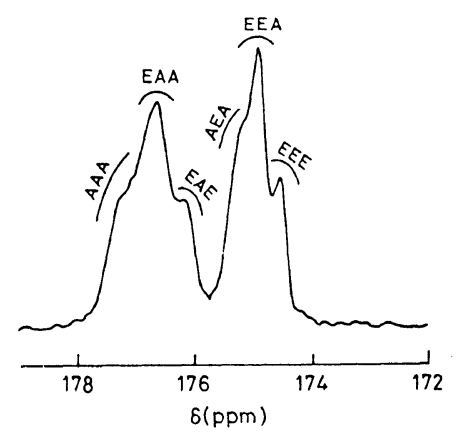

$$
\begin{gathered}
\mathrm{CH}_{2}-\underset{\mathrm{CONH}}{\mathrm{CH}}+\underset{\mathrm{C}}{\mathrm{C}}+\mathrm{COOCH}_{2}-\mathrm{CH}+ \\
\mathrm{CH}_{3} \mathrm{CH}_{3}
\end{gathered}
$$

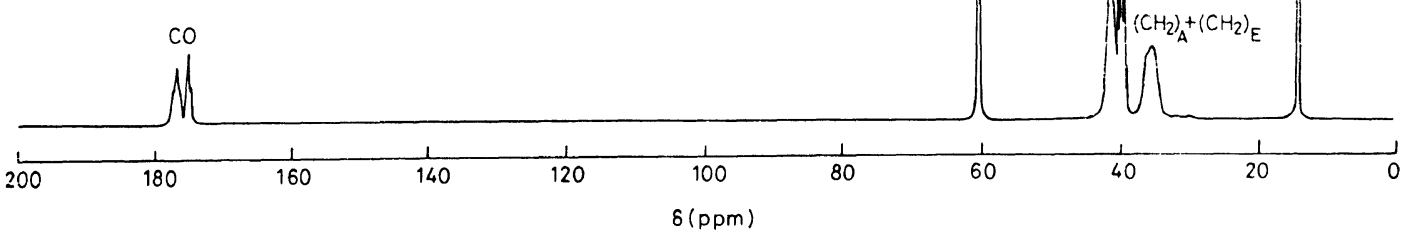

Figure 2. $75.5 \mathrm{MHz}{ }^{13} \mathrm{C}$ NMR spectrum of acrylamide/ethyl acrylate copolymer $\left(F_{\mathrm{A}}=0.50\right)$.
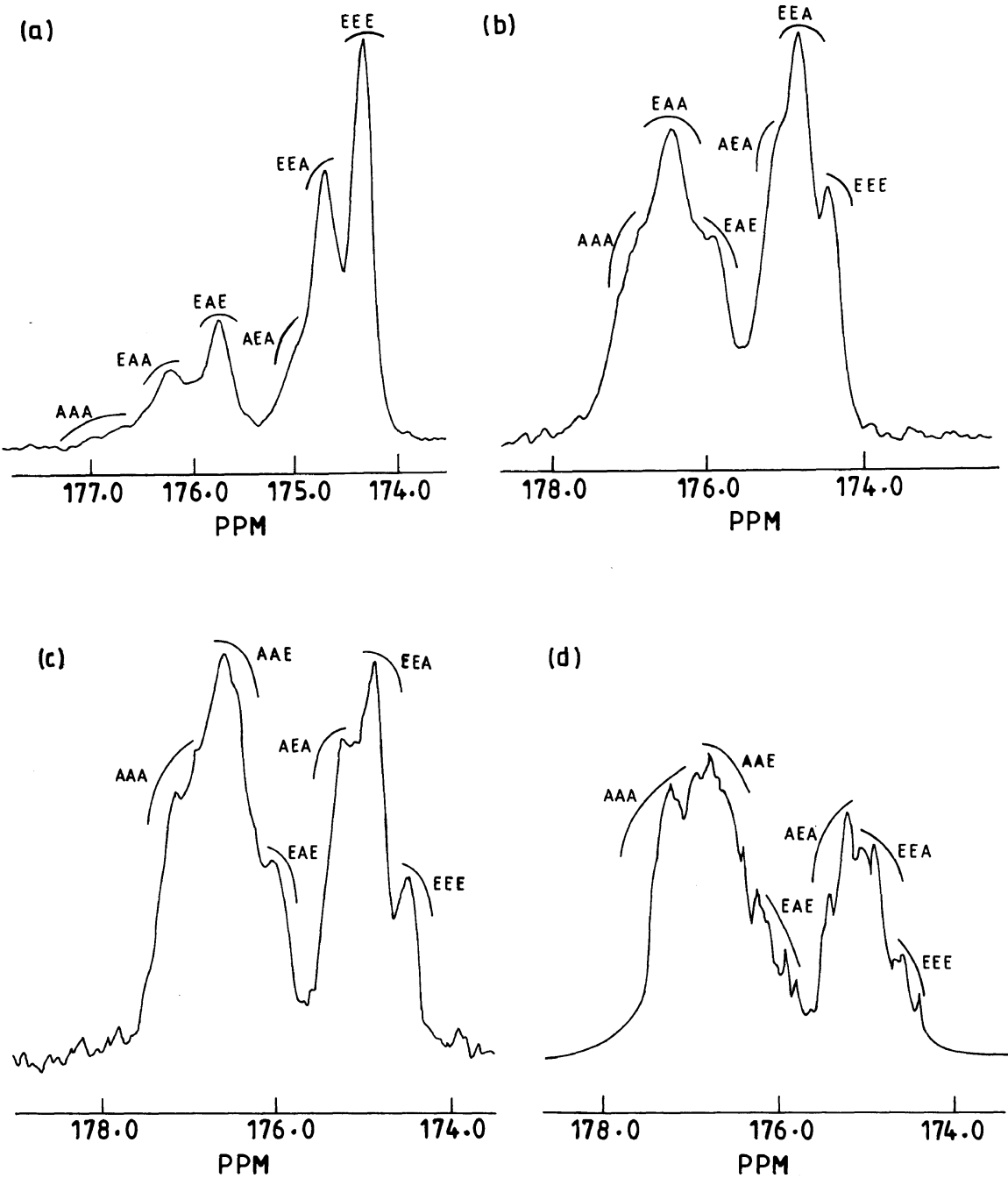

(d)

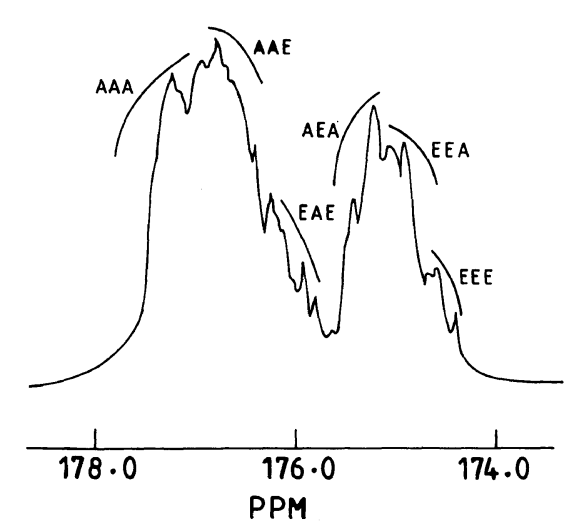

Figure 3. Expanded carbonyl $(\mathrm{C}=\mathrm{O})$ carbon resonance spectra for acrylamide/ethyl acrylate copolymer system of different feed compositions $\left(f_{\mathrm{A}}\right)($ a) 0.30, (b) 0.50, (c) 0.60 , and (d) 0.70 .

The concentrations of the A- and E-centered triads were calculated from the normalized areas of the respective signals. The triad fractions obtained from NMR were compared with the triad fractions calculated using the terminal model reactivity ratios $r_{\mathrm{A}}=0.59$ and
$r_{\mathrm{E}}=0.91$ from the Harwood's program ${ }^{14}$ assuming that Alfrey-Mayo model is valid at any moment of polymerization at low conversion. There is good agreement between the calculated and experimentally (NMR) determined triad fractions as shown in Table IV. The 

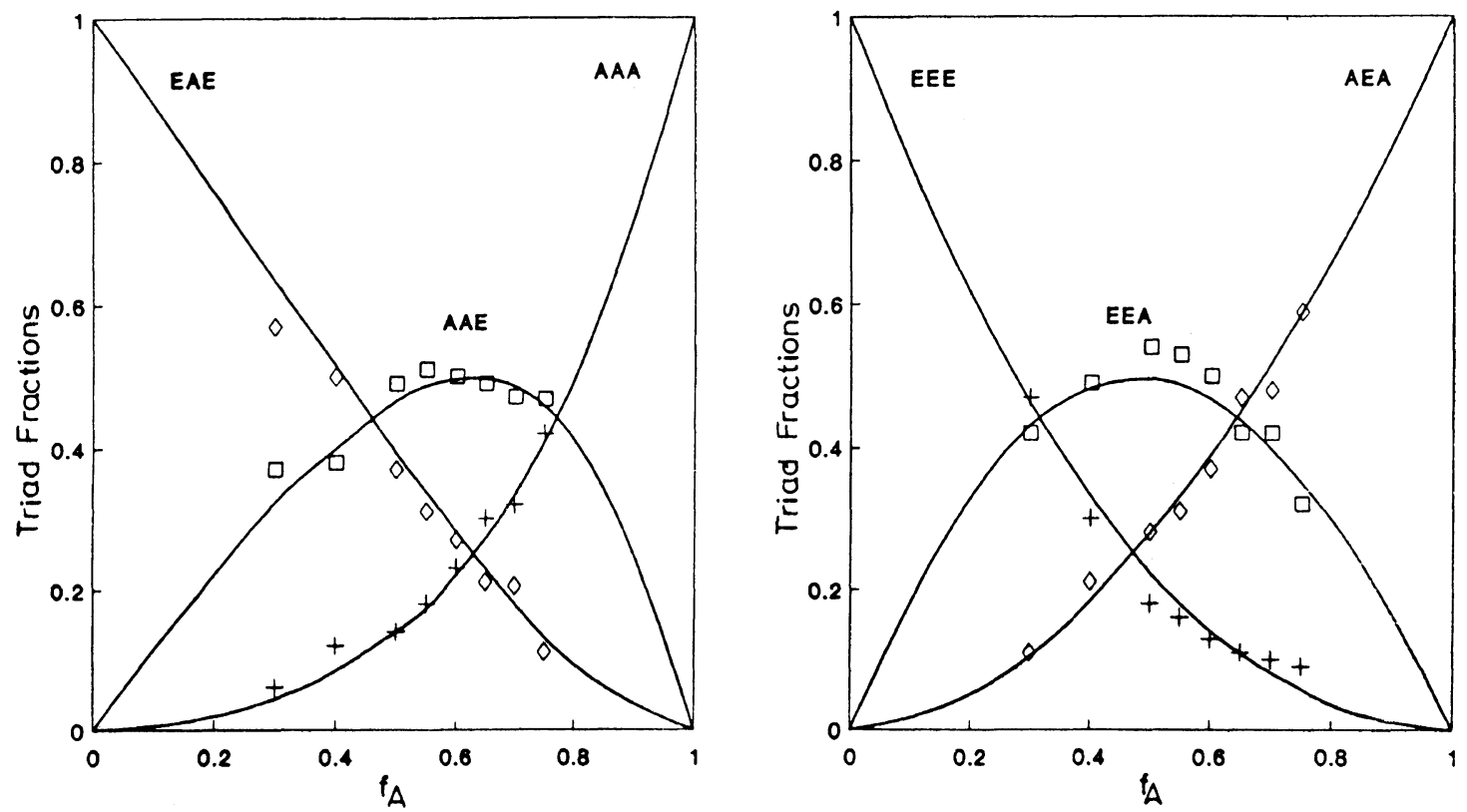

Figure 4. Variation of A- and E-centered triad fractions obtained from theoretical calculation (solid lines) and NMR spectroscopy (symbols) for the $\mathrm{A} / \mathrm{E}$ copolymer plotted against the feed mole fraction $\left(f_{\mathrm{A}}\right)$ of acrylamide.

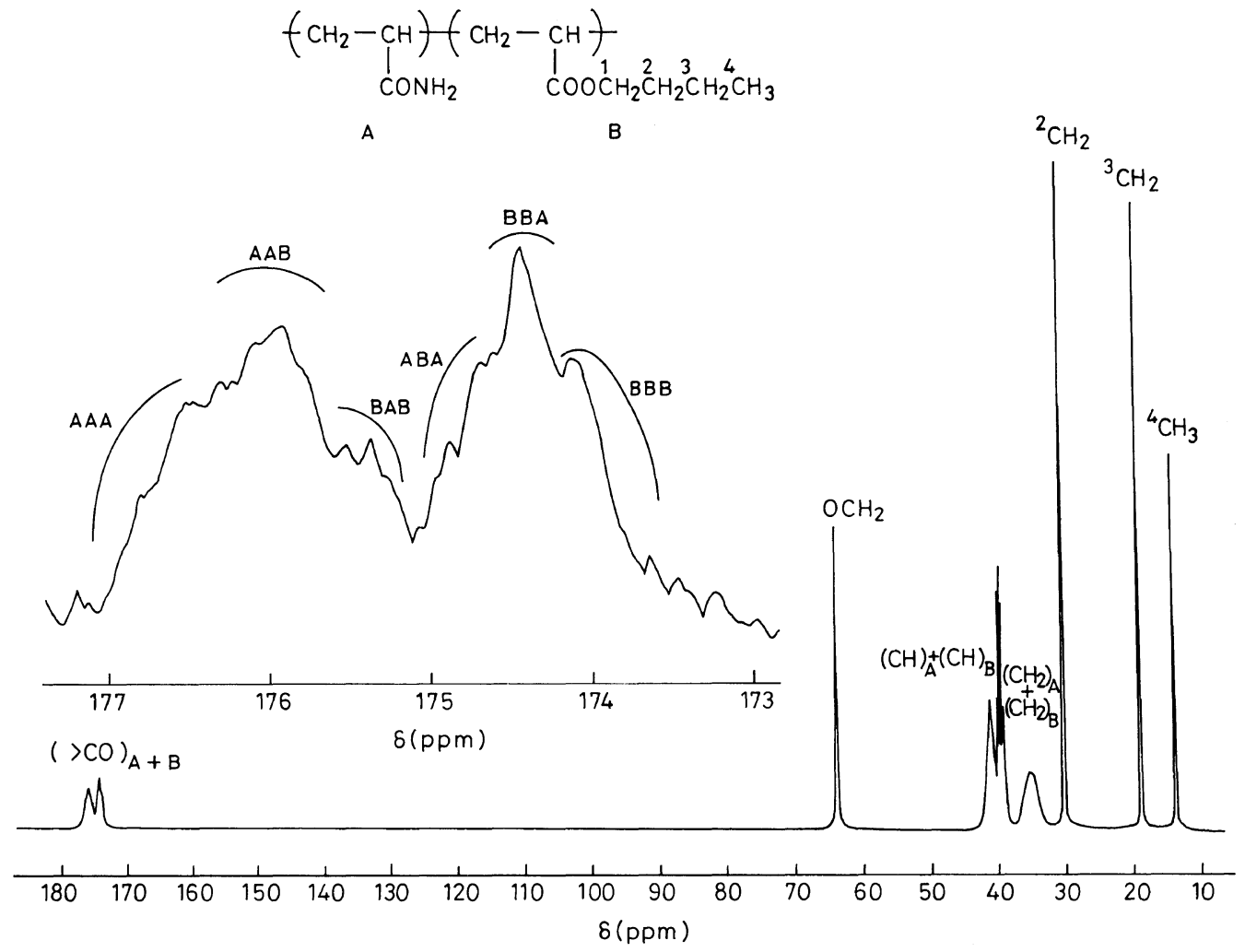

Figure 5. $75.5 \mathrm{MHz}{ }^{13} \mathrm{C}$ NMR spectrum of acrylamide/butyl acrylate copolymer $\left(F_{\mathrm{A}}=0.48\right)$.

correlation coefficient for NMR and Alfrey-Mayo data is $R=0.99$. Figure 4 shows variation of $\mathrm{A}$ - and $\mathrm{E}-$ centered triad fractions against the feed mole fraction of acrylamide. A constant increase in the AAA triad concentration and decrease in the EAE triad concentration was observed as $f_{\mathrm{A}}$ increases. The AAE(EAA) triad concentration first increases, passes through a maximum at 0.53 and then decreases with increase in $f_{\mathrm{A}}$. The same was noted for AEA and EEE triad concentration whereas the EEA(AEE) triad concentration showed a maximum at $f_{\mathrm{A}}=0.46$.
From the compositions of various $\mathrm{A}$ - and E-centered triads, conditional probabilities ${ }^{13} P_{\mathrm{E} / \mathrm{A}}$ and $P_{\mathrm{A} / \mathrm{E}}$ were calculated. $P_{\mathrm{E} / \mathrm{A}}$ decreases linearly from 0.76 to 0.35 as the E-unit in the copolymer decreases. $P_{\mathrm{A} / \mathrm{E}}$ increases linearly from 0.32 to 0.75 with increase in the content of A-unit in the copolymer. From the slopes of the respective plots of $1 /\left[P_{\mathrm{E} / \mathrm{A}}-1\right] v s . f_{\mathrm{A}} / f_{\mathrm{E}}$ and $1 /\left[P_{\mathrm{A} / \mathrm{E}}-1\right] v s . f_{\mathrm{E}} /$ $f_{\mathrm{A}}, r_{\mathrm{A}}$, and $r_{\mathrm{E}}$ were calculated as 0.62 and 0.87 , respectively. These values are within the experimental error of those calculated from the composition data.

Acrylamide/Butyl Acrylate $(A / B)$ Copolymers. Figure 
Table IV. Triad compositions calculated from NMR spectroscopy, Alfrey-Mayo model, and Monte Carlo simulation method for acrylamide/ ethyl acrylate $(\mathrm{A} / \mathrm{E})$ copolymers

\begin{tabular}{|c|c|c|c|c|c|}
\hline \multirow{2}{*}{$\begin{array}{c}\text { Sample } \\
\text { No. }\end{array}$} & \multirow{2}{*}{$\begin{array}{l}\text { Feed mole } \\
\text { fraction of } A\end{array}$} & \multirow[b]{2}{*}{ Triads } & \multicolumn{3}{|c|}{ Triad composition $^{a}$} \\
\hline & & & $\begin{array}{c}{ }^{13} \mathrm{C} \\
\mathrm{NMR}\end{array}$ & $\begin{array}{l}\text { Alfrey- } \\
\text { Mayo }\end{array}$ & $\begin{array}{l}\text { Monte } \\
\text { Carlo }^{b}\end{array}$ \\
\hline \multirow[t]{6}{*}{1} & \multirow[t]{6}{*}{0.30} & AAA & 0.06 & 0.04 & 0.02 \\
\hline & & AAE & 0.37 & 0.33 & 0.25 \\
\hline & & EAE & 0.57 & 0.63 & 0.73 \\
\hline & & EEE & 0.47 & 0.58 & 0.53 \\
\hline & & EEA & 0.42 & 0.36 & 0.40 \\
\hline & & AEA & 0.11 & 0.06 & 0.07 \\
\hline \multirow[t]{6}{*}{2} & \multirow[t]{6}{*}{0.40} & AAA & 0.12 & 0.08 & 0.06 \\
\hline & & $\mathrm{AAE}$ & 0.38 & 0.40 & 0.38 \\
\hline & & EAE & 0.50 & 0.52 & 0.56 \\
\hline & & EEE & 0.30 & 0.33 & 0.34 \\
\hline & & EEA & 0.49 & 0.49 & 0.49 \\
\hline & & AEA & 0.21 & 0.18 & 0.17 \\
\hline \multirow[t]{6}{*}{3} & \multirow[t]{6}{*}{0.50} & AAA & 0.14 & 0.14 & 0.13 \\
\hline & & $\mathrm{AAE}$ & 0.49 & 0.47 & 0.45 \\
\hline & & EAE & 0.37 & 0.39 & 0.42 \\
\hline & & EEE & 0.18 & 0.22 & 0.20 \\
\hline & & EEA & 0.54 & 0.50 & 0.50 \\
\hline & & AEA & 0.28 & 0.28 & 0.30 \\
\hline \multirow[t]{6}{*}{4} & \multirow[t]{6}{*}{0.55} & AAA & 0.18 & 0.17 & 0.17 \\
\hline & & $\mathrm{AAE}$ & 0.51 & 0.49 & 0.49 \\
\hline & & EAE & 0.31 & 0.34 & 0.34 \\
\hline & & $\mathrm{EEE}$ & 0.16 & 0.18 & 0.16 \\
\hline & & EEA & 0.53 & 0.49 & 0.49 \\
\hline & & AEA & 0.31 & 0.33 & 0.36 \\
\hline \multirow[t]{6}{*}{5} & \multirow[t]{6}{*}{0.60} & $\mathrm{AAA}$ & 0.23 & 0.22 & 0.24 \\
\hline & & AAE & 0.50 & 0.50 & 0.50 \\
\hline & & EAE & 0.27 & 0.28 & 0.26 \\
\hline & & EEE & 0.13 & 0.14 & 0.12 \\
\hline & & EEA & 0.50 & 0.47 & 0.44 \\
\hline & & AEA & 0.37 & 0.39 & 0.44 \\
\hline \multirow[t]{6}{*}{6} & \multirow[t]{6}{*}{0.65} & AAA & 0.30 & 0.27 & 0.29 \\
\hline & & $\mathrm{AAE}$ & 0.49 & 0.50 & 0.50 \\
\hline & & EAE & 0.21 & 0.23 & 0.21 \\
\hline & & EEE & 0.11 & 0.11 & 0.08 \\
\hline & & EEA & 0.42 & 0.44 & 0.42 \\
\hline & & AEA & 0.47 & 0.47 & 0.50 \\
\hline \multirow[t]{6}{*}{7} & \multirow[t]{6}{*}{0.70} & AAA & 0.32 & 0.33 & 0.37 \\
\hline & & $\mathrm{AAE}$ & 0.47 & 0.49 & 0.48 \\
\hline & & EAE & 0.21 & 0.18 & 0.15 \\
\hline & & EEE & 0.10 & 0.08 & 0.07 \\
\hline & & EEA & 0.42 & 0.40 & 0.39 \\
\hline & & AEA & 0.48 & 0.52 & 0.54 \\
\hline \multirow[t]{6}{*}{8} & \multirow[t]{6}{*}{0.75} & AAA & 0.42 & 0.41 & 0.40 \\
\hline & & AAE & 0.47 & 0.46 & 0.46 \\
\hline & & EAE & 0.11 & 0.13 & 0.14 \\
\hline & & EEE & 0.09 & 0.06 & 0.04 \\
\hline & & EEA & 0.32 & 0.35 & 0.33 \\
\hline & & AEA & 0.59 & 0.59 & 0.63 \\
\hline
\end{tabular}

${ }^{\mathrm{a}} \mathrm{A}$ and $\mathrm{E}$ centered triad fractions add up to unity. ${ }^{\mathrm{b}}$ Average standard deviation $(2 \sigma)$ is 0.025 .

5 shows a representative ${ }^{13} \mathrm{C}$ NMR spectrum of (A/B) copolymer $(\mathrm{A}=48 \mathrm{~mol} \%$ in the copolymer) along with signal assignments. The carbonyl carbons $(>\mathrm{C}=\mathrm{O})$ of A- and B-monomeric units appear as multiplets around $\delta 174.7-\delta 177.2$ and $\delta 173.0-\delta 175.5 \mathrm{ppm}$, respectively. Due to sensitivity towards compositional sequences, these signals were used to detremine the copolymerization mechanism. All other carbon resonances could not be used for sequence analysis because of insensitivity to microstructures (e.g., $-\mathrm{CH}_{3},-{ }^{2} \mathrm{CH}_{2},-{ }^{3} \mathrm{CH}_{2},-\mathrm{OCH}_{2}$ ), considerable overlap with each other (e.g., $\left[-\mathrm{CH}_{2}\right]_{\mathrm{A}}+$
Table V. Triad compositions calculated from NMR spectroscopy, Alfrey-Mayo model, and Monte Carlo simulation method for acrylamide/ butyl acrylate $(\mathrm{A} / \mathrm{B})$ copolymers

\begin{tabular}{|c|c|c|c|c|c|}
\hline \multirow{2}{*}{$\begin{array}{c}\text { Sample } \\
\text { No. }\end{array}$} & \multirow{2}{*}{$\begin{array}{c}\text { Feed mole } \\
\text { fraction of } A\end{array}$} & \multirow[b]{2}{*}{ Triads } & \multicolumn{3}{|c|}{ Triad composition $^{\mathbf{a}}$} \\
\hline & & & $\begin{array}{c}{ }^{13} \mathrm{C} \\
\mathrm{NMR}\end{array}$ & $\begin{array}{c}\text { Alfrey- } \\
\text { Mayo }\end{array}$ & $\begin{array}{l}\text { Monte } \\
\text { Carlo }^{\text {b }}\end{array}$ \\
\hline \multirow[t]{6}{*}{1} & \multirow[t]{6}{*}{0.30} & AAA & 0.11 & 0.06 & 0.05 \\
\hline & & $\mathrm{AAB}$ & 0.34 & 0.35 & 0.27 \\
\hline & & BAB & 0.55 & 0.59 & 0.68 \\
\hline & & $\mathrm{BBB}$ & 0.57 & 0.56 & 0.60 \\
\hline & & BBA & 0.34 & 0.38 & 0.32 \\
\hline & & $\mathrm{ABA}$ & 0.09 & 0.06 & 0.08 \\
\hline \multirow[t]{6}{*}{2} & \multirow[t]{6}{*}{0.40} & AAA & 0.12 & 0.10 & 0.08 \\
\hline & & $\mathrm{AAB}$ & 0.40 & 0.44 & 0.40 \\
\hline & & $\mathrm{BAB}$ & 0.48 & 0.46 & 0.52 \\
\hline & & BBB & 0.43 & 0.43 & 0.40 \\
\hline & & BBA & 0.45 & 0.45 & 0.48 \\
\hline & & $\mathrm{ABA}$ & 0.12 & 0.12 & 0.12 \\
\hline \multirow[t]{6}{*}{3} & \multirow[t]{6}{*}{0.50} & AAA & 0.15 & 0.17 & 0.15 \\
\hline & & $\mathrm{AAB}$ & 0.52 & 0.49 & 0.47 \\
\hline & & $\mathrm{BAB}$ & 0.33 & 0.34 & 0.38 \\
\hline & & $\mathrm{BBB}$ & 0.29 & 0.31 & 0.34 \\
\hline & & $\mathrm{BBA}$ & 0.49 & 0.49 & 0.48 \\
\hline & & $\mathrm{ABA}$ & 0.22 & 0.20 & 0.18 \\
\hline \multirow[t]{6}{*}{4} & \multirow[t]{6}{*}{0.55} & AAA & 0.21 & 0.22 & 0.20 \\
\hline & & $\mathrm{AAB}$ & 0.47 & 0.49 & 0.49 \\
\hline & & $\mathrm{BAB}$ & 0.31 & 0.29 & 0.31 \\
\hline & & $\mathrm{BBB}$ & 0.28 & 0.26 & 0.27 \\
\hline & & $\mathrm{BBA}$ & 0.48 & 0.50 & 0.50 \\
\hline & & $\mathrm{ABA}$ & 0.24 & 0.24 & 0.23 \\
\hline \multirow[t]{6}{*}{5} & \multirow[t]{6}{*}{0.60} & AAA & 0.30 & 0.27 & 0.28 \\
\hline & & $\mathrm{AAB}$ & 0.49 & 0.50 & 0.50 \\
\hline & & $\mathrm{BAB}$ & 0.21 & 0.23 & 0.22 \\
\hline & & BBB & 0.19 & 0.21 & 0.17 \\
\hline & & $\mathrm{BBA}$ & 0.52 & 0.49 & 0.49 \\
\hline & & $\mathrm{ABA}$ & 0.29 & 0.30 & 0.34 \\
\hline \multirow[t]{6}{*}{6} & \multirow[t]{6}{*}{0.65} & AAA & 0.36 & 0.33 & 0.38 \\
\hline & & $\mathrm{AAB}$ & 0.50 & 0.49 & 0.47 \\
\hline & & $\mathrm{BAB}$ & 0.14 & 0.18 & 0.14 \\
\hline & & BBB & 0.16 & 0.17 & 0.15 \\
\hline & & $\mathrm{BBA}$ & 0.47 & 0.48 & 0.45 \\
\hline & & $\mathrm{ABA}$ & 0.37 & 0.35 & 0.40 \\
\hline \multirow[t]{6}{*}{7} & \multirow[t]{6}{*}{0.70} & AAA & 0.42 & 0.39 & 0.43 \\
\hline & & $\mathrm{AAB}$ & 0.45 & 0.47 & 0.48 \\
\hline & & $\mathrm{BAB}$ & 0.13 & 0.14 & 0.09 \\
\hline & & BBB & 0.10 & 0.12 & 0.10 \\
\hline & & BBA & 0.46 & 0.46 & 0.43 \\
\hline & & $\mathrm{ABA}$ & 0.44 & 0.42 & 0.47 \\
\hline \multirow[t]{6}{*}{8} & \multirow[t]{6}{*}{0.75} & AAA & 0.49 & 0.46 & 0.45 \\
\hline & & $\mathrm{AAB}$ & 0.41 & 0.44 & 0.46 \\
\hline & & $\mathrm{BAB}$ & 0.10 & 0.10 & 0.09 \\
\hline & & BBB & 0.05 & 0.09 & 0.05 \\
\hline & & BBA & 0.41 & 0.42 & 0.40 \\
\hline & & $\mathrm{ABA}$ & 0.54 & 0.49 & 0.55 \\
\hline
\end{tabular}

${ }^{\mathrm{a}} \mathrm{A}$ and $\mathrm{B}$ centered triad fractions add up to unity. ${ }^{\mathrm{b}}$ Average standard deviation $(2 \sigma)$ is 0.025 .

$\left.\left[-\mathrm{CH}_{2}\right]_{\mathrm{B}}\right)$ or with DMSO- $d_{6}$ signals $\left(\right.$ e.g., $[-\mathrm{CH}]_{\mathrm{A}}+$ $\left.[-\mathrm{CH}]_{\mathrm{B}}\right)$.

The A- and B-centered triads were assigned on the basis of variation in the respective carbonyl $(=\mathrm{C}=\mathrm{O})$ signals with the copolymer composition. The assignment of the resonance signals to their respective triads and determination of the relative concentration of the triads were made in a similar way as for the A/E copolymer system. Thus the signals around $\delta 176.4-\delta 177.2$, $\delta 175.5-\delta 176.4$, and $\delta 174.7-\delta 175.5 \mathrm{ppm}$ were assigned to AAA, AAB(BAA), and BAB triads, respectively. The 

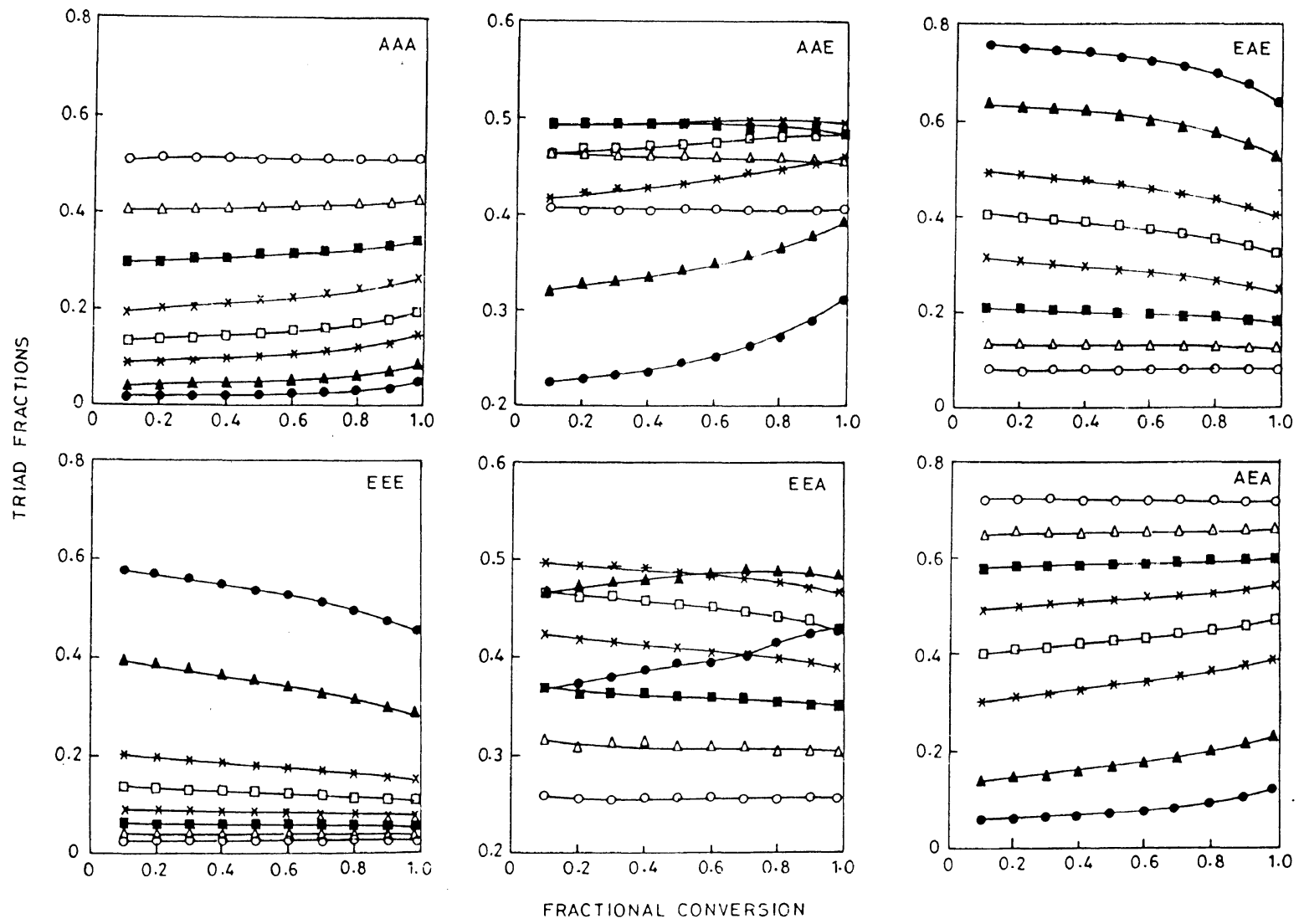

Figure 6. Variation of A- and E-centered triad fractions plotted as a function of fractional conversion for different feed mole fractions: $f_{\mathrm{A}}=0.30$ $(\bullet), f_{\mathrm{A}}=0.40(\boldsymbol{\Delta}), f_{\mathrm{A}}=0.50(*), f_{\mathrm{A}}=0.55(\square), f_{\mathrm{A}}=0.60(\times), f_{\mathrm{A}}=0.65(\boldsymbol{\square}), f_{\mathrm{A}}=0.70(\triangle)$, and $f_{\mathrm{A}}=0.75(\bigcirc)$.

resonance signals around $\delta 173.0-\delta 174.1, \delta 174.1-$ $\delta 174.6$, and $\delta 174.6-\delta 175.5 \mathrm{ppm}$ were assigned to $\mathrm{BBB}$, $\mathrm{BBA}(\mathrm{ABB})$, and $\mathrm{ABA}$ triads, respectively. The overlapping regions were resolved using a deconvoluting computer program.

The microstructure of $\mathrm{A} / \mathrm{B}$ copolymer in terms of the A- and B-centered triad sequence distribution from ${ }^{13} \mathrm{C}$ NMR was found to be in good agreement with the Alfrey Mayo model (First order Markov model) calculated by Harwood's program and Monte Carlo (MC) simulations using the reactivity ratios $r_{\mathrm{A}}=0.71$ and $r_{\mathrm{B}}=1.27$ (Table V). The correlation coefficient of NMR-Alfrey Mayo data is $R=0.99$ and NMR-MC is $R=0.97$. The variation of the $\mathrm{A}$ - and $\mathrm{B}$-centered triad fractions with feed mole fractions of A-unit is similar to $A / E$ copolymer system. The triad fractions AAA, ABA increases and $\mathrm{BAB}, \mathrm{BBB}$ decreases as $f_{\mathrm{A}}$ increases. The $\mathrm{AAB}$ and $\mathrm{ABB}$ triad fractions increase, go through a maximum at 0.57 and 0.52 , respectively, and then decrease as $f_{\mathrm{A}}$ increases.

The conditional probabilities $P_{\mathrm{B} / \mathrm{A}}$ and $P_{\mathrm{A} / \mathrm{B}}$ were calculated from the various $\mathrm{A}$ - and $\mathrm{B}$-centered triad concentrations. $P_{\mathrm{B} / \mathrm{A}}$ decreases linerly from 0.72 to 0.31 and $P_{\mathrm{A} / \mathrm{B}}$ increases from 0.26 to 0.75 with increase in acrylamide content in the copolymer. From the slopes of the respective plots of $1 /\left[P_{\mathrm{B} / \mathrm{A}}-1\right] v s . f_{\mathrm{A}} / f_{\mathrm{B}}$ and $1 /\left[P_{\mathrm{A} / \mathrm{B}}-1\right] v s . f_{\mathrm{B}} / f_{\mathrm{A}}, r_{\mathrm{A}}$, and $r_{\mathrm{B}}$ were calculated as 0.76 and 1.20 , respectively, which are within the experimental error of those found from compositional data.

\section{Monte Carlo (MC) Simulations}

Acrylamide/Ethyl Acrylate (A/E) Copolymer. The MC simulation method ${ }^{15}$ was used with NMR spectroscopy to monitor changes in the copolymer sequence behavior during polymerization. Triad concentrations obtained by the MC method were compared with the ones obtained from the NMR and the theoretical models. Results are given in Table $\mathrm{V}$. The correlation coefficient between the simulated (MC) and experimental data (NMR) is 0.96 indicating good agreement.

MC simulations can also be used to study the effects of the degree of polymerization on triad fractions. Figure 6 shows the variation of the A- and E-centered triad fractions as a function of fractional conversion for different feed mole fractions of acrylamide. Since the reactivity ratios of the two comonomer units are very close to each other $\left(r_{\mathrm{A}}=0.59\right.$ and $\left.r_{\mathrm{E}}=0.91\right)$, sharp variation of the individual triad fractions with fractional conversion was not observed. Figure 6 shows that when the feed mole fraction $\left(f_{\mathrm{A}}\right)$ is low $\left(f_{\mathrm{A}}<0.5\right)$, the AAA triad fraction increases only at higher conversion. Beyond $f_{\mathrm{A}}=0.5$, the AAA triad fraction starts increasing at lower conversion only, and change becomes almost constant for higher $f_{\mathrm{A}}$, i.e., $\left(f_{\mathrm{A}}>0.65\right)$. At higher feed mole fractions, the more reactive monomer (EA), being in lower concentration will be consumed at a fast rate initially. Thus the formation of the AAA units will start at lower conversion only. When $f_{\mathrm{A}}$ is low, the AAE triad fraction increases sharply at higher conversion. As $f_{\mathrm{A}}$ increases, increase in the AAE triad fraction becomes less significant. The EAE triad fraction shows an opposite trend to that shown by the AAA triad fraction. When $f_{\mathrm{A}}$ is low, the EAE triad fraction decreases sharply at higher conversion, but this decrease becomes less significant as $f_{\mathrm{A}}$ increases. The EEE triad fraction exhibits 
a sharp decrease at higher conversion when $f_{\mathrm{A}}$ is low. This is due to the fact that the E-units being more reactive and in larger proportion will combine rapidly with itself initially. Thus, the EEE triad concentration goes on decreasing as copolymerization progresses. As $f_{\mathrm{A}}$ increases, this decrease becomes less significant. The EEA triad fraction increases significantly with fractional conversion for low $f_{\mathrm{A}}$. However as $f_{\mathrm{A}}$ increases, this increase in EEA triad fraction becomes less. The third E-centered triad fraction (AEA) increase sharply at low conversions when $f_{\mathrm{A}}$ is low. As $f_{\mathrm{A}}$ increases, the AEA triad fraction start increasing at much lower conversions and for $f_{\mathrm{A}}>0.6$, the increase becomes less significant.

Acrylamide/Butyl Acrylate $(A / B)$ Copolymer. MC simulations were used to calculate variation of the triad concentrations with fractional conversions, which was found to be similar to that of the $\mathrm{A} / \mathrm{E}$ copolymer system.

\section{CONCLUSIONS}

The reactivity ratios of $\mathrm{A} / \mathrm{E}$ and $\mathrm{A} / \mathrm{B}$ copolymer systems were calculated by KT and EVM methods using the compositional data. Microstructures in terms of the triad distribution from ${ }^{13} \mathrm{C}$ NMR spectroscopy were found in good agreement with those calculated from the theoretical models and MC simulations using the terminal model reactivity ratios. The copolymerization mechanism was found to follow the first order Markov Model for both the copolymer systems. Variation in the triad concentrations with the degree of polymerization for the $\mathrm{A} / \mathrm{E}$ and $\mathrm{A} / \mathrm{B}$ copolymers was determined using MC simulations.

Acknowledgement. We are thankful to the University Grants Commission (UGC) for providing financial assistance for our work.

\section{REFERENCES}

1. F. A. Bovey, "Chain Structure and Conformation of Macromolecules," Academic Press, New York, N.Y., 1982.

2. P. K. Dhal, B. Vogt, A. Steigel, and G. Wulff, Macromolecules, 25, 5601 (1992)

3. J. M. Barton, J. Polym. Sci., C30, 573 (1970).

4. A. S. Brar and Sunita, J. Polym. Sci., Part A, Polym. Chem. Ed., 30, 2549 (1992).

5. F. Payne, "Organic Coating Technology," Vol. 1, John Wiley, New York, N.Y., 1964.

6. B. Srinivasulu, P. Raghunath Rao, E. V. Sundaram, J. Appl. Polym. Sci., 43, 1521 (1991).

7. N. D. Truong, J. C. Galin, J. Francois, and Q. T. Pham, Polymer, 27, 467 (1986).

8. K. Y. Park, E. R. Santef, and H. J. Harwood, Eur. Polym. J., 25, 651 (1989).

9. B. Srinivasulu, P. Raghunath Rao, E. V. Sundaram, M. Srinivas, and Lalitha Sirdeshmukh, Eur. Polym. J., 27, 979 (1991).

10. A. S. Brar, K. Dutta, and G. S. Kapur, Macromolecules, 28, 8735 (1995).

11. T. Kelen and F. J. Tüdos, J. Macromol. Sci. Chem., A9, 1 (1975).

12. M. Dubey, R. A. Sanyel, A. Penlidis, K. F. O'Driscoll, and P. M. Reilly, J. Polym. Sci., Polym. Chem. Ed., 29, 703 (1991).

13. J. L. Koenig, "Chemical Microstructure of Polymer Chains, Wiley-Interscience, New York, N.Y., 1980.

14. H. J. Harwood, J. Polym. Sci. C., 25, 37 (1968).

15. A. S. Brar, B. Jayaram, and K. Dutta, J. Polym. Mater., 10, 269 (1993). 